\title{
NATURAL VARIATIONS IN THE APPEARANCE AND THE POSITIONS OF THE MENTAL FORAMEN IN A SELECTED POPULATION OF KARACHI (PAKISTAN).
}

1. BDS, MSc-DS

PG Oral Surgery

Dr. Ishrat-ul-Ebad Khan Institute of Oral Health Sciences (DIKIOHS)

Dow University of Health Sciences.

2. BDS, FCPS

Senior Registrar Oral and

Maxillofacial Surgery

Dr. Ishrat-ul-Ebad Khan Institute of

Oral Health Sciences (DIKIOHS)

Dow University of Health Sciences Lahore.

3. BDS, MSc-DS

Lecturer Oral Medicine

Dr. Ziauddin University.

Correspondence Address:

Dr. Sara Fatima

Dr. Ishrat-ul-Ebad Khan Institute of

Oral Health Sciences (DIKIOHS)

Dow University of Health Sciences.

sara_fatima90@hotmail.com

Article received on:

01/11/2020

Accepted for publication:

$12 / 04 / 2020$

\begin{abstract}
Sara Fatima' ${ }^{1}$, Arfa Baig ${ }^{2}$, Aeman Ali $^{3}$
ABSTRACT... Objectives: The purpose of this study is to evaluate the most common appearance, horizontal and vertical positions of the mental foramen (MF), using the panoramic radiographs in a selected population of Karachi (Pakistan). As this is relevant to consider prior to plan any maxillofacial surgical procedures in order to avoid nerve injuries. Study Design: Cross-sectional study. Setting: Radiology Department of the Dr. Ishrat ul Ebad khan institute of oral health sciences (Dow University of Health Sciences). Period: $25^{\text {th }}$ September to $5^{\text {th }}$ November 2018. Material \& Methods: Total 500 panoramic images were assessed. The study was divided in to the two group i.e. male and female adult patients in which the appearance, anterior-posterior positions and the superior-inferior positions of the MF was analyzed on the panoramic radiographs. Results: Total 500 OPG were accessed, the age ranges between 12 years to 73 years, 229 were male, 271 were females, and majority of MF were separated type $(n=341,68.2 \%)$ on right side and $(n=373,74.6 \%)$ on left side. And the most common superioinferior position of the MF on both sides were position 2 (below the level of apices of $1^{\text {st }}$ and $2^{\text {nd }}$ premolar) on right side $(n=387,77.4 \%)$ and on left side $(n=376,75.2 \%)$, and the most common anterio-posterior position of the MF on both the right and left side is position 4 ( M.F lies in the line of $2^{\text {nd }}$ premolars $)$, on right side $(n=269,53.8 \%)$ and on left side $(n=255,51 \%)$. Conclusion: In this study the "separated type" was the most common type of appearance in both genders and the most frequent superio-inferior position of the MF is below the level of apices of $1^{\text {st }}$ and $2^{\text {nd }}$ premolar on both right and left sides. And the most common anterior-posterior position is within the line of longitudinal axis of $2^{\text {nd }}$ premolar on both sides.
\end{abstract}

Key words: $\quad$ Mental Foramen, Mandible, Mental Nerve, Panoramic Radiograph.

Article Citation: Fatima S, Baig A, Ali A. Natural variations in the appearance and the positions of the mental foramen in a selected population of Karachi (Pakistan). Professional Med J 2020; 27(6):1267-1274.

DOI: 10.29309/TPMJ/2020.27.06.4314

\section{INTRODUCTION}

The localization of the mental foramen is important for various clinical and diagnostic purposes in the maxillofacial surgery. ${ }^{1} \mathrm{MF}$ is difficult to localize because of lack of its fixed anatomical location. ${ }^{2,3}$ The position of MF may varies among individuals to individuals in its locations, appearances and size. ${ }^{1}$ The appearance of the MF is funnel like opening, ${ }^{4}$ located on the antero-lateral aspects of the body of mandible ${ }^{5-7}$ where the mental canal terminates, midway between the inferior border of mandible and the alveolar margins, ${ }^{8}$ It usually felt as a depression. .,6,9 $^{\text {The shape of }}$ the MF can be rounded or oval anywhere below or between the premolars. ${ }^{10}$ and the variations in location observed from the mandibular canines to the first molars. ${ }^{11}$ Usually, one foramen is present on each side but the number can be vary according to some studies and even the absence of foramina have also been reported unilaterally and bilaterally. ${ }^{10}$

The surgical anatomy is, the third division of the trigeminal nerve is the mandibular nerve, which leave the skull from the foramen ovale ${ }^{12}$ which further divides in to two branches, i.e. smaller anterior \& the larger posterior branch. The posterior branch gives off the lingual and the inferior alveolar nerve. The inferior alveolar nerve enters in to the mandible from the mandibular foramen which runs in to a bony canal, called mandibular canal below the lower teeth. Which then exit the mandibular canal and then further divide in to the mental nerve, which emerges 
from a foramen called mental foramen, which further give off its three branches i.e. one branch descends towards the skin of the chin. ${ }^{13}$ And the remaining two branches ascends towards the mucous membranes and the skin of lower lip. ${ }^{14}$

The wall of the foramen composed of cortical bone. ${ }^{15}$ The position of MF is about $2.8-4 \mathrm{~cm}$ from the symphysis menti (the median fusion of two half parts of the mandible). In vertical axis, it lies in the lower half of the mandible. Horizontally, MF opens in higher position from the inferior alveolar canal. ${ }^{16,17}$ And most of the MF are oriented posterio-superioly. ${ }^{18}$

According to some cadaveric studies, MF is described as rounded in $(34.48 \%)$ with $(1.68 \mathrm{~mm})$ average diameter and (65.52\%) is oval foramen with average diameter of $(2.37 \mathrm{~mm}) .{ }^{19}$ The mean diameter of MF reported as $3.8 \mathrm{~mm} .{ }^{10}$ According to Philips et al study, the average size of MF is $4.6 \mathrm{~mm}$ horizontally and $3.4 \mathrm{~mm}$ vertically. ${ }^{20,21}$ The Accessory mental foramen reported usually below the $1^{\text {st }}$ molar teeth. ${ }^{22}$ The incidence of AMF on one side (unilaterally) is $2 \%-10^{23,24}$

The mental nerve injury may causes permanent or temporary paraesthesia of gingiva of anterior region, chin and lower lip. ${ }^{25}$ The mental nerve is more prone to injuries during many minor and major invasive procedures i.e. during administering regional and local anesthesia ${ }^{26}$, periapical surgical procedure, exodontia, surgical orthodontics, for curettage of premolar region, periosteal dissection, endodontic treatments, osteotomies, cosmetics surgeries, implant placement. During implant placement, there is a possibility that the mental nerve's anterior loop may present mesially to the MF which is very important to consider during planning, to avoid neurosensory disturbances in the region of chin and lower lip, reduction and fixation in the region of mandibular body region, orthodontic tooth movement, useful in increasing frequency of orthognathic surgical procedures, preprosthetic surgeries, also important for estimation of alveolar bridge resorption and MF also provide aid in interpreting anatomical landmark in the oral and forensic pathology. ${ }^{18,10,20,27}$
Radiography is one of the best non-invasive and simple method for the assessment of the location of MF. ${ }^{28}$ The panoramic radiographs are the curved planes topographic techniques, have certain advantages such as, it aid view of the entire body of mandible with clear view of the MF in both vertical and horizontal dimensions. And greater coverage of hard and soft tissues. with minimum radiations exposure. ${ }^{29}$ In the recent years, many advanced and improved radiographic techniques are accessible i.e. computerized tomography (C.T scan) which shows the mandible in three dimensions. These advanced techniques have several drawbacks i.e. they are expensive, they are not available easily in every kind of dental setups and hospitals, and the most importantly the exposure of radiations doses is much higher as compared to conventional radiography. ${ }^{30}$

\section{MATERIAL \& METHODS}

This Descriptive Cross Sectional Study was conducted at the Radiology Department of the Dr. Ishrat ul Ebad khan institute of oral health sciences (Dow University of Health Sciences). And Non-probability consecutive sampling was done. Total 500 panoramic radiographs of adult patients was selected from $25^{\text {th }}$ September to $5^{\text {th }}$ November 2018. All radiographs were captured by the same technician, using the Rotograph's EVOD machine by the Villa Sistemi Medicali Buccinasco Italy, with the exposure parameter (8mA, $68 \mathrm{kV}, 13.8 \mathrm{~s})$. Then observed appearance, vertical and horizontal positions of MF of both right and left side with age and gender. Only those OPG's was selected which fulfilled our inclusion criteria's.

\section{Inclusion Criteria}

- Radiographs of adult patients, having all permanent teeth.

- MF must be clearly visible on both the right \& left sides of the mandible.

- All the lower premolar\& 1st molar tooth must be present.

- High quality (grade1) radiographs should be considered, according to the angulations and contrasts.

- OPG's were made anonymous, having 
patients age and gender only.

\section{Exclusion Criteria}

- Radiographs having incomplete eruption of teeth or mixed dentition

- Radiographs having superimposition of structures, any artifact or any positional errors

- Radiographs of those patients undergoing orthodontic treatment

- Radiographs with crowded, drifted, supernumerary and rotated lower teeth and radiolucent/radiopaque lesions in the MF region.

All the radiographs were analyzed for appearances and positions by using following classifications.

Al-Khateeb classified the superior-inferior position of $\mathrm{MF}^{31}$,

1. Above the level of the apices of the $1^{\text {st }}$ and $2^{\text {nd }}$ premolars

2. Below the level of the apices of the $1^{\text {st }}$ and $2^{\text {nd }}$ premolars

3. At the level of the apices of the $1^{\text {st }}$ and $2^{\text {nd }}$ premolars

According to the Yosue and Brooks the type of appearances of the MF was classified $\mathrm{as}^{32}$,

Type 1: continuous type: MF has continuity with the mandibular canal.

Type 2: separated type: MF separated from the canal, appear as well defined radiolucent distinct borders

Type 3: diffuse type: MF has indistinct borders Type 4: unidentified type: MF is not visible
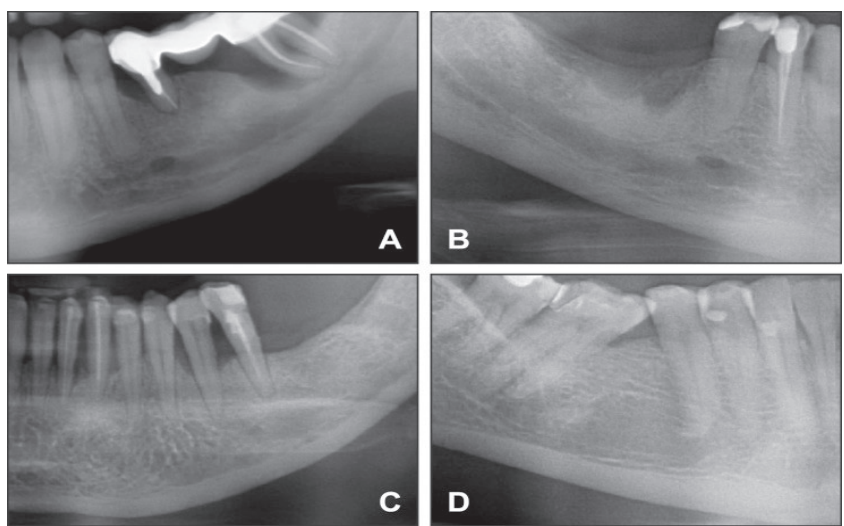

Figure-1. The appearance of MF on panoramic radiograph, according to Yosue and Brooks classification A: continuous type, B: separated type, C: diffuse type, D: unidentified type ${ }^{33}$
Tebo and Telford classified the anterior-posterior position of MF as ${ }^{34}$,

Position 1: MF lying along the longitudinal axis which passed $\mathrm{b} / \mathrm{w}$ a canine and $1^{\text {st }}$ premolar.

Position 2: MF lying along the longitudinal axis of $1^{\text {st }}$ premolar.

Position 3: MF lying along the longitudinal axis passed $\mathrm{b} / \mathrm{w} 1^{\text {st }} \& 2^{\text {nd }}$ premolars.

Position 4: MF lying along the longitudinal axis of $2^{\text {nd }}$ premolar.

Position 5: MF lying the longitudinal axis passed $\mathrm{b} / \mathrm{w}$ the $2^{\text {nd }}$ premolar \& $1^{\text {st }}$ molar.

Position 6: MF lying along the longitudinal axis of $1^{\text {st }}$ molar.

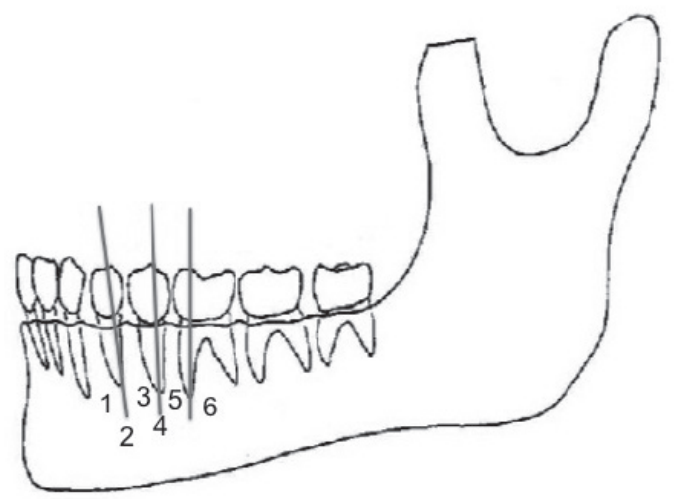

1. MF lying on a longitudinal axis passed between the canine and 1st premolar

2. MF lay on the longitudinal axis of 1st premolar

3. MF lying on the longitudinal axis which passed between the 1st and 2nd premolar.

4. MF lying on the longitudinal axis of 2nd premolar.

5. MF lying on the longitudinal axis which passed between the 2nd premolar and the 1st molar.

6. MF that lay on the longitudinal axis of the 1st molar.

Figure-2. Position of MF with reference to teeth, according to Tebo and Telford classification

The dependent variables are, the appearance, superio-inferior and the anterio-posterior positions of the MF, on both left and right sides of the mandible. The Independent variables includes, Age and gender. Frequencies and percentages of the variables were calculated.

\section{RESULTS}

Total 500 OPG was selected, age ranges from 12 years to 73 years. Out of 500 radiographs, 229 (45.8\%) were male and 271 (54.2\%) were female. 


\section{AGE RANGE}

Regarding the appearance of MF (right side), the most common type is "Separated type" with the frequency of 341 (68.2\%) which then followed by continuous type with frequency of $153(30.6 \%)$. Unidentified type was not found.

On left side of mandible, the most common

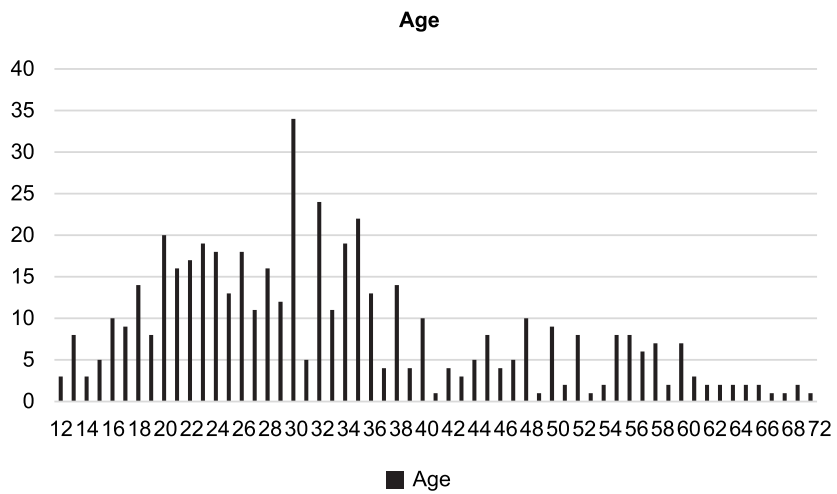

type of appearance of MF was also "Separated type" with frequency of $373(74.6 \%)$ followed by continuous type 119 (23.8\%).

The most common superior-inferior position (right side) of MF was found "below the level of apices of $1^{\text {st }}$ and $2^{\text {nd }}$ premolar" with frequency of 387 (77.4\%). Which then followed by "at the level of apices of $1^{\text {st }}$ and $2^{\text {nd }}$ premolar" with frequency of $107(21.4 \%)$.

The most common superior-inferior position of MF (left side) was found "below the level of apices of $1^{\text {st }}$ and $2^{\text {nd }}$ premolar" with frequency of 376 (75.2\%), followed by "at the level of apices of $1^{\text {st }}$ and $2^{\text {nd }}$ premolar" with frequency of 117 (23.4\%).

Regarding anterio-posterior position of MF (right side), the most common position is found in "the line of longitudinal axis of $2^{\text {nd }}$ premolar" with frequency of 269 (53.8\%) which then followed by "in the line of longitudinal axis passed $b / w$ the $1^{\text {st }}$ and $2^{\text {nd }}$ premolar" with frequency of $142(28.4 \%)$.

The most common anterior-posterior position of MF (left side) was found "in the line of longitudinal axis of $2^{\text {nd }}$ premolar" with frequency of $255(51 \%)$, followed by $184(36.8 \%)$ in the line of longitudinal axis passed between the $1^{\text {st }}$ and $2^{\text {nd }}$ premolar.

\begin{tabular}{|l|c|c|c|c|}
\hline \multicolumn{1}{|c|}{ Appearance } & $\begin{array}{c}\text { Frequency } \\
\text { (Right) }\end{array}$ & Percent (Right) & $\begin{array}{c}\text { Frequency } \\
\text { (Left) }\end{array}$ & $\begin{array}{c}\text { Percent } \\
\text { (Left) }\end{array}$ \\
\hline Continuous Type & 153 & 30.6 & 119 & 23.8 \\
\hline Separated Type & 341 & 68.2 & 373 & 74.6 \\
\hline Diffuse Type & 6 & 1.2 & 8 & 1.6 \\
\hline Total & 500 & 100 & 500 & 100 \\
\hline
\end{tabular}

Table-I. Appearance of mental foramen (Right and left sides)

\begin{tabular}{|l|c|c|c|c|}
\hline \multicolumn{1}{|c|}{ Superior-Inferior Position } & $\begin{array}{c}\text { Frequency } \\
\text { (Right) }\end{array}$ & $\begin{array}{c}\text { Percent } \\
\text { (Right) }\end{array}$ & $\begin{array}{c}\text { Frequency } \\
\text { (Left) }\end{array}$ & $\begin{array}{c}\text { Percent } \\
\text { (Left) }\end{array}$ \\
\hline Above the level of apices of $1^{\text {st }}$ and $2^{\text {nd }}$ premolar & 6 & 1.2 & 7 & 1.4 \\
\hline Below the level of apices of $1^{\text {st }}$ and $2^{\text {nd }}$ premolar & 387 & 77.4 & 376 & 75.2 \\
\hline At the level of apices of $1^{\text {st }}$ and $2^{\text {nd }}$ premolar & 107 & 21.4 & 117 & 23.4 \\
\hline Total & 500 & 100 & 500 & 100 \\
\hline
\end{tabular}

Table-II. Superio-inferior position (Right and left sides) 


\begin{tabular}{|c|c|c|c|c|}
\hline Anterior-Posterior Position & $\begin{array}{l}\text { Frequency } \\
\text { (Right) }\end{array}$ & $\begin{array}{l}\text { Percent } \\
\text { (Right) }\end{array}$ & $\begin{array}{l}\text { Frequency } \\
\text { (Left) }\end{array}$ & $\begin{array}{l}\text { Percent } \\
\text { (Left) }\end{array}$ \\
\hline $\begin{array}{l}\text { M.F lay on the longitudinal axis passed b/w } \\
\text { canine and 1st premolar }\end{array}$ & 13 & 2.6 & 13 & 2.6 \\
\hline M.F lay on the longitudinal axis of 1st premolar & 19 & 3.8 & 13 & 2.6 \\
\hline $\begin{array}{l}\text { M.F lay on the longitudinal axis passed b/w 1st } \\
\text { and 2nd premolar }\end{array}$ & 142 & 28.4 & 184 & 36.8 \\
\hline M.F lay on the longitudinal axis of 2 nd premolar & 269 & 53.8 & 255 & 51.0 \\
\hline $\begin{array}{l}\text { M.F lay on the longitudinal axis passed b/w 2nd } \\
\text { premolar and 1st molar }\end{array}$ & 50 & 10.0 & 31 & 6.2 \\
\hline M.F lay on the longitudinal axis of 1 st molar & 7 & 1.4 & 4 & 0.8 \\
\hline
\end{tabular}

\section{DISCUSSION}

Mental nerve injuries may cause permanent, transitory sensitivity, thermal and tactile changes. ${ }^{25}$ Sharawy et.al states that the nerve injuries usually occurs because of nerve stretching, compression, totally or partially nerve transection which may causes, Paraesthesia (numbness), anesthesia (complete loss of the sensation), dysthesia (painful feelings), hyperesthesia (increased sensitivity) or hypoesthesia (reduced sensation) of the lower teeth, lip, surrounding skin \& mucosa. It may occur while performing osteotomies ${ }^{36}$, also venous and arterial bleeding may occur. ${ }^{37}$

The radiographs should have clearly visible MF bilaterally, so that the appearance, superior-inferior(vertical) and the anteriorposterior(horizontal) positions can be assessed on both sides of mandible among males and females. ${ }^{2}$ The shape and density and the definition of the border of MF on the radiograph varies. ${ }^{20}$ Sometimes, the identification of the MF becomes difficult on OPG due to increase in bone density. ${ }^{4,28}$ The position of MF change according to the development of mandible from birth to the old age. In infants, the MF is located somewhere posteriorly, below the bud of $1^{\text {st }}$ molar. As the permanent teeth erupts, the MF moves anteriorly to its final position that corresponds to the level of $2^{\text {nd }}$ premolar. In neonates, the position of MF is closer to alveolar margin then with the eruption of permanent teeth, it descends $\mathrm{b} / \mathrm{w}$ the alveolar and the inferior margin. In old age, MF found closer to the alveolar margin due to the bone resorption and the loss of teeth. ${ }^{19,38,39}$

The position of MF varies among different ethnic groups and genders having different dental occlusion and craniofacial skeletal structure. ${ }^{40}$ The study conducted on dry adult mandibles from the South Indian population, also concluded that in majority of the mandibles have MF at the level of the root of $2^{\text {nd }}$ premolar, midway $b / w$ the alveolar and the inferior margins of the mandible. ${ }^{8}$ Another study done in North American population and the data is collected from the dried skulls of the white population of north America to access the normal range of the position of MF and they have concludes, the most frequent position of MF is between the $1^{\text {st }}$ and $2^{\text {nd }}$ premolars. ${ }^{41}$

A study conducted among the population of UK, the most common position of the MF is $\mathrm{b} / \mathrm{w}$ the 1st and 2nd premolars. ${ }^{42}$ According to the study conducted among Malay population, the most frequent position of MF is in the line of the $2^{\text {nd }}$ premolar, ${ }^{4}$ followed by position b/w the $1^{\text {st }}$ and $2^{\text {nd }}$ premolars. And according to some studies conducted among the Saudi, Indians and Singaporean population, the MF is most commonly found in the line of the 2 nd premolar. ${ }^{43}$ Among Korean population MF is coincided most commonly with the lower $2^{\text {nd }}$ premolar. $^{44}$ According to another study, the most commonly found appearance of MF was the continuous type with respect to the mandibular canal. The most frequent superior-inferior position is, below the level of the apices of the premolar. The most 
frequent anterior-posterior position of the MF is $\mathrm{b} / \mathrm{w}$ the $1^{\text {st }}$ and $2^{\text {nd }}$ premolars. ${ }^{2}$

Further recommendations are to evaluate MF with two different approaches i.e. assessment on radiographs with analysis on dry skulls. And analysis of MF can also be done with measuring distances from the other important anatomical landmarks of the mandible which can provide more help to clinician for preoperative planning of different surgical procedures.

\section{CONCLUSION}

In this study, total 500 panoramic radiographs were accessed which shows satisfactory visibility and which fulfilled our inclusion criteria. Age ranges between 12 to 73 years. Out of 500 OPG, 229 were male $(45.8 \%)$ and 271 were female $(54.2 \%)$. From this study, we conclude that the majority of MF were of "separated type" on both sides. On right side $(n=341,68.2 \%)$ and on left side $(n=373,74.6 \%)$ followed by continuous type on both sides. And the most common superiorinferior position of MF on both sides were position 2 (below the level of apices of $1^{\text {st }}$ and $2^{\text {nd }}$ premolar) on right side $(n=387,77.4 \%)$ and on left side $(n=376,75.2 \%)$, followed by position 1 (above the level of apices of $1^{\text {st }} \& 2^{\text {nd }}$ premolar) on both sides. And the most common anterio-posterior position of MF on both left and right sides is position 4 ( M.F lies on the longitudinal axis of $2^{\text {nd }}$ premolar $)$, on right side $(n=269,53.8 \%)$ and on left side $(n=255,51 \%)$ followed by position 3 (M.F lies on the longitudinal axis passed b/w the 1st \& 2nd premolars). No difference is observed on right and left side.

\section{Copyright@ 12 Apr, 2020.}

\section{REFERENCES}

1. Gupta V, Pitti P, Sholapurkar A. Panoramic radiographic study of mental foramen in selected dravidians of south Indian population: A hospital based study. Journal of clinical and experimental dentistry. 2015; 7(4):e451.

2. Dehghani M, Ghanea S. Position of the mental foramen in panoramic radiography and its relationship to age in a selected Iranian population. Avicenna Journal of Dental Research. 2016; 8(1).
3. Rupesh S, Winnier JJ, John SA, Joy T, Rao AP, Reddy V. Radiographic study of the location of mental foramen in a randomly selected Asian Indian population on digital panoramic radiographs. J Med Sci. 2011; $11(2): 90-5$.

4. Ngeow WC, Yuzawati Y. The location of the mental foramen in a selected Malay population. Journal of oral science. $2003 ; 45(3): 171-5$.

5. Fishel D, Buchner A, Hershkowith A, Kaffe I. Roentgenologic study of the mental foramen. Oral surgery, oral medicine, and oral pathology. 1976; $41(5): 682-6$.

6. Al Faleh $\mathrm{W}$, Zahrani A. Observer agreement in the radiographic assessment of mental foramen appearance on panoramic radiographs. Pakistan Oral Dent J. 2005; 25(2):225-8.

7. Igbigbi PS, Lebona S. The position and dimensions of the mental foramen in adult Malawian mandibles. West African journal of medicine. 2005; 24(3):184-9.

8. Udhaya K, Saraladevi K, Sridhar J. The morphometric analysis of the mental foramen in adult dry human mandibles: A study on the South Indian population. Journal of clinical and diagnostic research: JCDR. 2013; $7(8): 1547$.

9. Punjabi SK, ur Rehman $\mathrm{BH}$, Haider M. Radiographic position of mental foramen in selected Pakistani population. JPDA. 2010; 19(2):106.

10. Punjabi S. Radiographic position of mental foramen in selected Pakistani population 2010. 105-9 p.

11. Budhiraja V, Rastogi R, Lalwani R, Goel P, Bose SC. Study of position, shape, and size of mental foramen utilizing various parameters in dry adult human mandibles from north India. ISRN anatomy. 2012; 2013.

12. Woolfall $P$, Coulthard $A$. Trigeminal nerve: Anatomy and pathology. The British journal of radiology. 2001; 74(881):458-67.

13. Tewfik TL, Meyers A. Trigeminal nerve anatomy. Available from emedicine medscape com/ article/1873373-overview\# show all [Accessed October, 2015]. 2013.

14. Gray's Anatomy (1918) $20^{\text {th }}$ edition, page 897 .

15. Phillips JL, Weller RN, Kulild JC. The mental forman: Part I. Size, orientation, and positional relationship to the mandibular second premolar. Journal of endodontics. 1990; 16(5):221-3. 
16. Smajilagić A, Dilberović F. Clinical and anatomy study of the human mental foramen. Bosnian journal of basic medical sciences. 2004; 4(3):15-23.

17. Souaga K, Adou A, Angoh Y. [Topographical and morphological study of the mandibular foramen in black Africans from the Ivory Coast]. Odontostomatologie tropicale $=$ Tropical dental journal. 2004; 27(105):17-21.

18. Udhaya K, Saraladevi K, Sridhar J. The morphometric analysis of the mental foramen in adult dry human mandibles: A study on the South Indian population. Journal of clinical and diagnostic research: JCDR. 2013; $7(8): 1547$.

19. Gershenson A, Nathan H, Luchansky E. Mental foramen and mental nerve: Changes with age. Acta anatomica. 1986; 126(1):21-8.

20. Verma P, Bansal N, Khosa R, Verma K, Sachdev S, Patwardhan $\mathrm{N}$, et al. Correlation of radiographic mental foramen position and occlusion in three different Indian populations. The West Indian Medical Journal. 2015; 64(3):269.

21. Phillips JL, Weller RN, Kulild JC. The mental forman: Part I. Size, orientation, and positional relationship to the mandibular second premolar. Journal of endodontics. 1990; 16(5):221-3.

22. Cağirankaya L, Kansu H. An accessory mental foramen: A case report. J Contemp Dent Pract. 2008; 9(1):98-104.

23. Igarashi C, Kobayashi K, Yamamoto A, Morita Y, Tanaka M. Double mental foramina of the mandible on computed tomography images: A case report. Oral Radiology. 2004;20(2):68-71.

24. Zografos J, Mutzuri A. [Incidence of double mental foramen in a sample of Greek population]. Odontostomatologike proodos. 1989; 43(6):521-3.

25. Amorim MM, Prado FB, Borini CB, Bittar TO, Volpato MC, Groppo FC, et al. The mental foramen position in dentate and edentulous Brazilian's mandible. Int J Morphol. 2008; 26(4):981-7.

26. Babshet M, Sandeep $R$, Burde K, Nandimath K. Evaluation of the position of mental foramen and its correlation with age in selected Indian population using digital panoramic radiograph. Int $\mathrm{J}$ Dent Sci Res. 2015; 3(4):87-91.

27. Al-Juboori MJ, Hua CM, Yuen KY. The importance of the mental foramen location detection by using different radiographic technique: Mini review. Malay. 2014; 169(69.2):19.6.
28. Afkhami F, Haraji A, Boostani HR. Radiographic localization of the mental foramen and mandibular canal. Journal of dentistry (Tehran, Iran). 2013; 10(5):436.

29. Gada SK, Nagda SJ. Assessment of position and bilateral symmetry of occurrence of mental foramen in dentate Asian population. Journal of clinical and diagnostic research: JCDR. 2014; 8(2):203.

30. Jamdade AS, Bhayana SYR, Khare V, Pardhe N, Mathur $\mathrm{N}$. Radiographic localization of mental foramen in a selected Indian population. Innovative Journal of Medical and Health Science. 2013; 3(5).

31. Al-Khateeb T, Hamasha AA-H, Ababneh KT. Position of the mental foramen in a northern regional Jordanian population. Surgical and Radiologic Anatomy. 2007; 29(3):231-7.

32. Yosue T, Brooks SL. The appearance of mental foramina on panoramic and periapical radiographs: II. Experimental evaluation. Oral Surgery, Oral Medicine, Oral Pathology. 1989; 68(4):488-92.

33. Juodzbalys G, Wang H-L, Sabalys G. Anatomy of mandibular vital structures. Part II: mandibular incisive canal, mental foramen and associated neurovascular bundles in relation with dental implantology. Journal of oral \& maxillofacial research. 2010;1(1).

34. Tebo HG, Telford IR. An analysis of the variations in position of the mental foramen. The Anatomical Record. 1950; 107(1):61-6.

35. Abed H, Bakhsh A, Hazzazi L, Alzebiani N, Nazer F. Anatomical variations and biological effects of mental foramen position in population of Saudi Arabia. Dentistry. 2016; 6(373):2161-1122.1000373.

36. Sharawy M, Misch C. Anatomy for dental implants. Contemporary Implant Dentistry, 2nd ed St Louis: The CV Mosby Company. 1999:217-24.

37. Jalbout Z, Tabourian G. Glossary of implant dentistry: ICOI; 2004.

38. Kanchan T, KriShan K. Mental foramen in prediction of age. Journal of clinical and diagnostic research: JCDR. 2015; 9(6):GJ01.

39. Lipski M, Tomaszewska I, Lipska W, Lis G, Tomaszewski K. The mandible and its foramen: Anatomy, anthropology, embryology and resulting clinical implications. Folia morphologica. 2013; 72(4):285-92. 
40. Baxmann M. Mental paresthesia and orthodontic treatment. The Angle Orthodontist. 2006; 76(3):533-7.

41. Moiseiwitsch JR. Position of the mental foramen in a North American, white population. Oral surgery, oral medicine, oral pathology, oral radiology, and endodontics. 1998; 85(4):457-60.

42. Currie CC, Meechan JG, Whitworth JM, Carr A, Corbett IP. Determination of the mental foramen position in dental radiographs in 18-30 year olds. Dentomaxillofacial Radiology. 2015; 45(1):20150195.
43. Neo J. The position of the mental foramen in Singaporean Malays and Indians. Anesthesia progress. $1989 ; 36(6): 276$.

44. Lim J-S, Min K-H, Lee J-H, Lee H-K, Hong S-H. Anthropometric analysis of facial foramina in Korean population: A three-dimensional computed tomographic study. Archives of craniofacial surgery. 2016; 17(1):9.

\begin{tabular}{|c|l|l|l|}
\hline \multicolumn{3}{|c}{ AUTHORSHIP AND CONTRIBUTION DECLARATION } \\
\hline Sr. \# & \multicolumn{1}{|c|}{ Author(s) Full Name } & Contribution to the paper & Author(s) Signature \\
\hline 1 & Sara Fatima & 1st Author & \\
\hline 2 & Arfa Baig & 2nd Author & \\
\hline 3 & Aeman Ali & 3rd Author & \\
\hline
\end{tabular}

